\title{
Extralobar pulmonary sequestration with a cyst: a case report
}

\author{
Jian $\mathrm{Li}^{1}$, Yingmei Jiang ${ }^{1}$, Jiarong Xiao ${ }^{1}$, Guiyou Liang ${ }^{2}$ \\ ${ }^{1}$ Department of Thoracic Surgery, The Affiliated Hospital of Guizhou Medical University, Guiyang, China; ${ }^{2}$ Guizhou Medical University, Guiyang, \\ China \\ Correspondence to: Guiyou Liang. Guizhou Medical University, No.28 Guiyi street, Guiyang 550000, China. Email: guiyou515@163.com.
}

\begin{abstract}
Extralobar pulmonary sequestration (EPS) is a congenital malformation. In contrast with intralobar sequestration, EPS located outside the normal lung tissue and with a distinct pleural covering. In the current case report, we present a rare case of EPS. To our knowledge, this is the first report of a cyst occurring within the EPS. A 17-year-old male patient presented with chest pain for 1 month. Computed tomography (CT) scan demonstrated a sharply circumscribed mass at the left side of the lower thoracic vertebrae. No aberrant vessel was observed on contrast-enhanced CT. The preoperative diagnosis was a posterior mediastinal tumor or EPS and surgical resection was recommended to the patient. During the operation, an extrapulmonary sequestration lobe was found in the left chest cavity. There was an aberrant artery connecting the sequestration lobe and the descending aorta. A cyst was located in the apex of the sequestration lobe. Surgical resection was performed via thoracoscopy. The postoperative histopathology confirmed an extrapulmonary sequestration combined with a cyst. The patient recovered successfully and was discharged on the sixth day postoperatively. He did not present with recurrent chest pain at the 6-month follow up. EPS should be considered when a posterior mediastinal conical mass is shown on chest CT.
\end{abstract}

Keywords: Extralobar pulmonary sequestration (EPS); pulmonary cyst; thoracoscopy; case report

Submitted Mar 19, 2020. Accepted for publication Jul 04, 2020.

doi: $10.21037 /$ atm-20-3815

View this article at: http://dx.doi.org/10.21037/atm-20-3815

\section{Introduction}

Extralobar pulmonary sequestration (EPS) is a rare congenital malformation, and its most significant feature is a lack of connection with the normal tracheobronchial tree (1). It was thought that some small, asymptomatic EPS did not need medical intervention. However, due to the potential risk of infection, hemorrhage, and malignant transformation, surgical resection is recommended to patients with EPS in recent years (2). Surgical resection is the standard treatment and used to be performed by thoracotomy. Recently, more cases can be operated by thoracoscopy. Here, we present a rare case of EPS resected via thoracoscopy. In other reported cases, EPS occurred with congenital diaphragmatic hernia, pericardial defects, chest wall deformities, and other congenital anomalies. EPS was completely isolated from adjacent normal lung tissues by an independent pleura, other lung diseases rarely occur within this lesion. This is the first case reporting a cyst within the EPS. We present the following case in accordance with the CARE reporting checklist (available at http://dx.doi.org/10.21037/atm-20-3815).

\section{Case presentation}

A 17-year-old male patient presented with chest pain for 1 month. He had not suffered cough, hemoptysis, respiratory distress, fever, or wheezing, and no family history of congenital pulmonary malformation was identified. Physical examination was negative. Computed tomography (CT) scan demonstrated a sharply circumscribed mass in the posterior mediastinum (Figure 1A). No aberrant vessel was observed on contrast-enhanced CT.

The preoperative diagnosis was a posterior mediastinal tumor or EPS. Surgical resection via a thoracoscopic approach was recommended to the patient. He was administered general anesthesia with double-lumen endotracheal intubation and was placed in a right lateral 

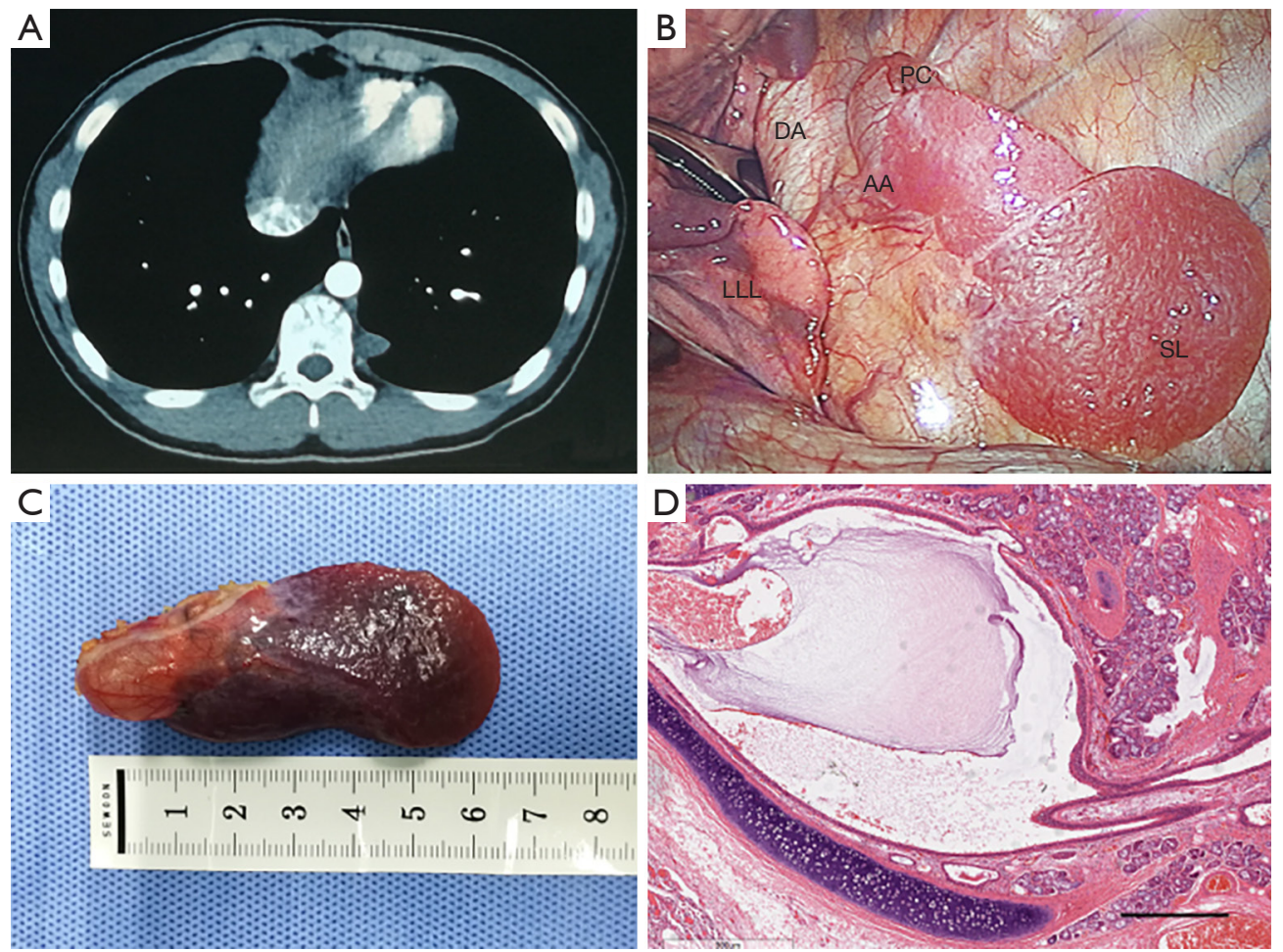

Figure 1 (A) Computed tomography scan demonstrating a sharply circumscribed mass in the posterior mediastinum. (B) A cyst located in the apex of sequestration lobe and an aberrant artery communicating the sequestration lobe and the descending aorta. (C) The morphology of the lesion. (D) The pathologic features of the sequestration lobe and cyst (hematoxylin and eosin stain, magnification $\times 10$ ). LLL, left lower lobe; DA, descending aorta; SL, sequestration lobe; AA, aberrant artery; PC, pulmonary cyst).

position. One port was placed in the seventh intercostal space at the mid-axillary line, one port was placed the fourth intercostal of the anterior axillary line, and one port was placed the ninth intercostal space at the rear of the posterior axillary line.

During the operation, an extrapulmonary sequestration lobe without a connection to the tracheobronchial tree was found in the left chest cavity (Figure 1B). There was an aberrant artery communicating the sequestration lobe and descending aorta. A cyst was located in the apex of sequestration lobe. After ligation and division of the vascular pedicle with a $2-\mathrm{mm}$ vascular staple, the mass was completely resected. The longest diameter of the lesion was $6.5 \mathrm{~cm}$ (Figure 1C). The postoperative histopathology confirmed an extrapulmonary sequestration combined with a cyst (Figure 1D). The patient was given antibiotics for one day and analgesic for five days after operation. The patient recovered uneventfully and was discharged on the sixth postoperative day (Figure 2). At 6-month follow-up, he did not present with chest pain.
All procedures performed in this study involving human participants were in accordance with the Declaration of Helsinki (as revised in 2013). Written informed consent was obtained from the patient for publication of this manuscript.

\section{Discussion}

Pulmonary sequestration (PS) is a rare congenital malformation. The significant anatomic features of PS include a lack of connection with the normal tracheobronchial tree, and a blood supply arising from the descending aorta or other systemic arteries $(1,3)$. Therefore, pulmonary sequestrations are nonfunctional lung tissues. According to whether exists an own visceral pleura, PS can be divided into intralobar sequestration and EPS (3). PS which is located in the normal lung and shares a common visceral pleura is considered an intralobar sequestration, while PS located outside the normal lung tissue and with a distinct pleural covering is considered to be EPS.

Though EPS can occur in the chest cavity, diaphragm, 


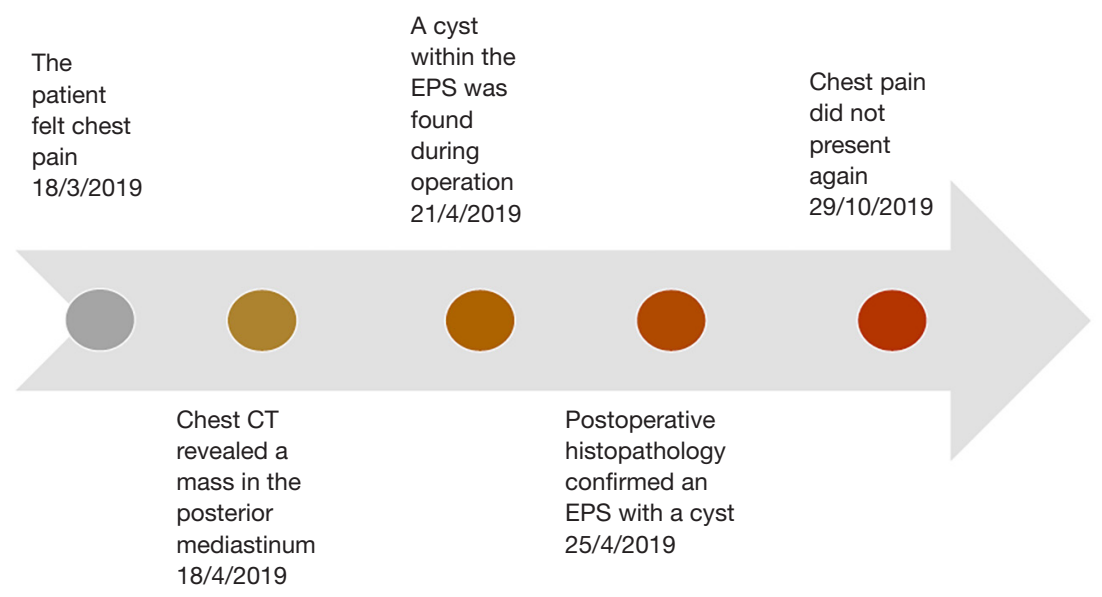

Figure 2 Timeline of major clinical events in the patient.

and abdomen, most cases of EPS have been found in the left hemithorax and located between the left lower lobe and the diaphragm $(4,5)$. Other congenital anomalies are often coexistent in many patients with EPS, including congenital diaphragmatic hernia, another congenital lung abnormality, pericardial defects and cysts, chest wall deformities, hindgut duplications, etc. $(6,7)$.

Patients with EPS may present hypoxia, feeding difficulties, respiratory symptoms, and cardiac failure without a cardiac cause in infancy (8-10). The investigations for EPS include chest X-ray, ultrasound, magnetic resonance imaging, and CT (11-13). Compared with other diagnostic modalities, chest CT demonstrates the complex mass more clearly. The features on the CT scan for EPS include a mass or a cyst near the spine and with an arterial supply mainly originating from the descending aorta. Indeed, most aberrant blood vessels can be found by enhanced CT. Unfortunately, although we did enhance CT before the operation, no abnormal blood vessels were found in this case. To avoid misdiagnosis for EPS, we suggest that an angiography should be done before operation. Histologically, the EPS was consisted of dilated airways lined by bronchiolar type epithelium and remnants of cartilaginous bronchi.

Patients with EPS are at risk of infection, hemorrhage, and malignant transformation. Therefore, surgical resection is recommended (2). Resection can be performed via thoracotomy or video-assisted thoracic surgery $(4,14,15)$. The key point of the operation procedure is to identify and carefully manage the aberrant blood vessels.

There were several limitations in the management of this case. The preoperative diagnosis was not sufficiently accurate, and thus high resolution CT should be performed before surgery. Furthermore, whether surgery is superior to conservative treatment is difficult to prove through this single case.

In conclusion, we report a rare case of EPS with a cyst. Most of the masses in the posterior mediastinum are neurogenic, but a few may be EPS, even if there are no obvious abnormal blood vessels identified on chest CT. Preoperative high-resolution enhanced CT and angiography can avoid misdiagnosis. In addition, thoracoscopy is safe and feasible for the treatment of EPS without serious infection. It is important to carefully identify and deal with abnormal blood vessels.

\section{Acknowledgments}

Funding: None.

\section{Footnote}

Reporting Checklist: The authors have completed the CARE reporting checklist. Available at http://dx.doi.org/10.21037/ atm-20-3815

Conflicts of Interest: All authors have completed the ICMJE uniform disclosure form (available at http://dx.doi. org/10.21037/atm-20-3815). The authors have no conflicts of interest to declare.

Ethical Statement: The authors are accountable for all 
aspects of the work in ensuring that questions related to the accuracy or integrity of any part of the work are appropriately investigated and resolved. All procedures performed in this study involving human participants were in accordance with the Declaration of Helsinki (as revised in 2013). Written informed consent was obtained from the patient for publication of this manuscript.

Open Access Statement: This is an Open Access article distributed in accordance with the Creative Commons Attribution-NonCommercial-NoDerivs 4.0 International License (CC BY-NC-ND 4.0), which permits the noncommercial replication and distribution of the article with the strict proviso that no changes or edits are made and the original work is properly cited (including links to both the formal publication through the relevant DOI and the license). See: https://creativecommons.org/licenses/by-nc-nd/4.0/.

\section{References}

1. Petersen G, Martin U, Singhal A, et al. Intralobar sequestration in the middle-aged and elderly adult: recognition and radiographic evaluation. J Thorac Cardiovasc Surg 2003;126:2086-90.

2. Laurin S, Aronson S, Schuller H, et al. Spontaneous hemothoraz from bronchopulmonary sequestration: unusual angiographic and pathologic-anatomic findings. Pediatr Radiol 1980;10:54-6.

3. Fu S, Wang H. Pulmonary sequestration associated with a synchronous elevation of carbohydrate antigen 50 and 199: a case report. Ann Transl Med 2018;6:212.

4. Savic B, Birtel FJ, Tholen W, et al. Lung sequestration: report of seven cases and review of 540 published cases. Thorax 1979;34:96-101.

5. DeParedes CG, Pierce WS, Johnson DG. Pulmonary

Cite this article as: Li J, Jiang Y, Xiao J, Liang G. Extralobar pulmonary sequestration with a cyst: a case report. Ann Transl Med 2020;8(15):969. doi: 10.21037/atm-20-3815 sequestration in infants and children: a 20-year experience and review of the literature. J Pediatr Surg 1970;5:136-47.

6. Conran RM, Stocker JT. Extralobar sequestration with frequently associated congenital cystic adenoid malformation, type 2: Report of 50 cases. Pediatr Dev Pathol 1999;2:454-463.

7. Murray ME, Given-Wilson RM, Jeffrey IJM. Bilateral communicating bronchopulmonary foregut malformations in an infant with multiple congenital anomalies. Pediatr Radiol 1994;24:128-30.

8. White JJ, Donahoo JS, Ostrow PT, et al. Cardiovascular and respiratory manifestations of pulmonary sequestration in childhood. Ann Thorac Surg 1974;18:286-94.

9. Crushell E, Said A, Al-Hassan A, et al. Occlusion of an aberrant artery to a pulmonary sequestration using a duct occluder. J Interv Cardiol 2002;15:415-6.

10. Tokel K, Boyvat F, Varan B. Coil embolization of pulmonary sequestration in two infants: a safe alternative to surgery. AJR Am J Roentgenol 2000;175:993-5.

11. Deeg KH, Hofbeck M, Singer H. Diagnosis of intralobar lung sequestration by colour-coded Doppler sonography. Eur J Pediatr 1992;151:710-2.

12. Ikezoe J, Murayama S, Godwin JD, et al. Bronchopulmonary sequestration: CT assessment. Radiology 1990;176:375-9.

13. Kouchi K, Yoshida H, Matsunaga T, et al. Intralobar bronchopulmonary sequestration evaluated by contrastenhanced three-dimensional MR angiography. Pediatr Radiol 2000;30:774-5.

14. Mezzetti M, Dell'Agnola CA, Bedoni M, et al. Videoassisted thorascopic resection of pulmonary sequestration in an infant. Ann Thorac Surg 1996;61:1836-7.

15. Albanese CT, Sydorak RM, Tsao K, et al. Thorascopic lobectomy for prenatally diagnosed lung lesions. J Pediatr Surg 2003;38:553-5. 